Revue d'histoire de l'Amérique française

W REVUE D.HISTOIRE DE L'AMÉRIQUE FRANÇAISE

\title{
BILODEAU, Rosario, Robert COMEAU, André GOSSELIN, Denise JULIEN, Histoire des Canadas. Montréal, Éditions Hurtubise HMH, Ltée, 1971. 676 p., cartes, index. \$9.75.
}

\section{Antonin Dupont}

Volume 26, numéro 1, juin 1972

URI : https://id.erudit.org/iderudit/303155ar

DOI : https://doi.org/10.7202/303155ar

Aller au sommaire du numéro

Éditeur(s)

Institut d'histoire de l'Amérique française

ISSN

0035-2357 (imprimé)

1492-1383 (numérique)

Découvrir la revue

Citer ce compte rendu

Dupont, A. (1972). Compte rendu de [BILODEAU, Rosario, Robert COMEAU, André GOSSELIN, Denise JULIEN, Histoire des Canadas. Montréal, Éditions Hurtubise HMH, Ltée, 1971. 676 p., cartes, index. \$9.75.] Revue d'histoire de l'Amérique française, 26(1), 106-107. https://doi.org/10.7202/303155ar d'utilisation que vous pouvez consulter en ligne.

https://apropos.erudit.org/fr/usagers/politique-dutilisation/ 


\section{COMPTES RENDUS}

Bilodeau, Rosario, Robert Comeau, André Gosselin, Denise JULIEN, Histoire des Canadas. Montréal, Editions Hurtubise HMH, Ltée, 1971. 676 p., cartes, index. \$9.75.

La parution d'une nouvelle synthèse en histoire du Canada est un événement que l'on doit toujours souligner. Plus encore si l'œuvre est le fruit de longues et patientes recherches et le résultat d'un travail admirable de collaboration.

Nous n'avons pas l'intention de faire une critique exhaustive de l'ouvrage mais plutôt de mettre en évidence quelques temps forts et de signaler quelques imperfections qu'une lecture cursive nous a permis de constater.

L'aspect culturel, au sens obvie du terme, nous semble fort bien traité dans l'ouvrage et apporte souvent un éclairage nouveau relativement à d'autres synthèses. L'éducation sous le régime français (pp. 82-83-106) et au début du régime anglais (pp. 310-311), le rôle du clergé après 1837 (pp. 378-391), la guerre des éteignoirs (p. 391) reçoivent une plus grande importance. De même, au XXe siècle, les écoles de l'Ontario et le règlement XVII (pp. 515-516-517), la pensée nationaliste (pp. 493-494), l'Ecole sociale populaire (p. 554) et le Rapport Tremblay (pp. 586-587) sont assez abondamment commentés.

Parlant des lois adoptées par le gouvernement québécois au début de la décennie de 1920, les auteurs affirment qu' "aucune de ces lois n'était audacieuse" (p. 536). L'affirmation est assez juste si l'on songe à l'ensemble du Canada. Il faut cependant reconnaître que la loi de l'Assistance publique de 1921 rompait avec une tradition québécoise vieille de plus de 300 ans. Par ailleurs, il n'est nulle part fait mention de la loi des alcools de 1921, loi qui étatisait la vente des spiritueux et faisait du Québec le seul Etat de l'Amérique du Nord où la prohibition n'avait pas droit de cité.

Lorsqu'il est question de l'établissement d'un impôt provincial sur le revenu en février 1954, les auteurs laissent entendre que la loi votée par l'Assemblée législative du Québec "s'inspirait du Rapport de la Commission Tremblay" (p. 588). Or le rapport n'a été rendu public, par le premier ministre Maurice Duplessis, que le 6 avril 1956.

A la fin de chacun des chapitres de la synthèse, on suggère une liste d'ouvrages à consulter. Si l'on a voulu fournir "au lecteur des références aux documents les plus accessibles [et] le voir s'informer lui-même de son histoire" (Intr.), il nous apparaît étrange que l'on n'ait pas conseillé la consultation de l'œuvre de Robert Rumilly. A notre avis, et quels que soient les sentiments que l'on entretienne envers cette œuvre, on ne peut prétendre étudier l'histoire du Québec en faisant abstraction du travail de recherche

RHAF, vol. 26, no 1 (juin 1972) 
déjà accompli par cet historien. Sans insister davantage, nous aimerions exprimer notre désaccord quant à l'omission de certaines études dans la bibliographie suggérée. A côté de l'ouvrage de A. Raynauld, Institutions économiques canadiennes, nous aurions voulu retrouver l'ouvrage de Roger-J. Bédard, L'Essor économique du Québec. En même temps que l'on suggère la brochure de Marcel Trudel, Le Régime seigneurial, il aurait été de mise, croyons-nous, de mentionner l'ouvrage de Richard Harris, The Seigneurial System in Early Canada. Il deviendrait fastidieux de poursuivre une telle énumération, d'autant plus que l'on peut différer d'avis sans que l'œuvre en soit dévalorisée.

Un bon nombre d'ouvrages que l'on destine à un vaste public souffrent d'une carence fondamentale: la difficulté de consultation. Quelques-unes des meilleures synthèses d'histoire du Canada n'échappent pas à cette tare. Il faut reconnaître que l'Histoire des Canadas a réussi à faciliter la tâche du lecteur en ajoutant un index de matières à l'index des noms de personnes. Qu'il nous soit permis également de noter la clarté et la simplicité des cartes qui jalonnent la période coloniale française. Une interrogation demeure toutefois: comment expliquer l'absence de toute représentation cartographique dans les deux dernières parties de l'ouvrage? Au cours des deux derniers siècles, l'espace canadien a subi de profondes transformations qu'il aurait été utile d'illustrer afin de faciliter la compréhension des événements.

Nous sommes heureux de souligner la rigueur du style qui caractérise l'ouvrage. Toutefois, nous ne pouvons accepter que l'on utilise les termes "législature" (p. 468) et "unions" (p. 551) au sens où ils sont employés. Nous convenons qu'il est parfois difficile d'abandonner certaines expressions sans trahir la réalité historique. Ainsi, notre terminologie politique a longtemps accepté les titres bouffons de "secrétaire provincial" et de "procureur général". L'historien est souvent obligé de les utiliser, sinon il ferait croire au lecteur que le ministère de l'Education, par exemple, a été créé avant 1964, au Québec.

La dernière partie de l'ouvrage plus que les deux premières adopte une approche que peu de volumes d'histoire du Canada ont présentée jusqu'à maintenant. Cette originalité confère une valeur incontestable à l'ensemble et nous incite à en recommander la lecture. Le curieux des choses de son pays, l'amateur d'histoire aussi bien que celui qui fait métier d'enseigner le passé se doivent d'avoir lu l'Histoire des Canadas.

ANTONIN DUPont

Service des Etudes

Commission des Ecoles catholiques de Montréal 